\title{
Endovascular Management of Cerebral Aneurysm: The Recent Trends
}

\author{
Vipul Gupta ${ }^{1}$ Shrikant Londhe ${ }^{1}$ Rajsrinivas Parthasarathy ${ }^{1} \quad$ Hilal Ahmad Ganaie $^{1}$
}

${ }^{1}$ Department of Interventional Neuroradiology, Artemis Agrim Institute of Neurosciences, Gurgaon, Haryana, India

\author{
Address for correspondence Vipul Gupta, MD, Department \\ of Interventional Neuroradiology, Artemis Agrim Institute of \\ Neurosciences, Gurgaon, Haryana, India \\ (e-mail: drvipulgupta25@gmail.com).
}

\begin{abstract}
Keywords

- cerebral aneurysm

- coiling

- flow diverter

Cerebral aneurysm rupture is the leading cause of mortality and morbidity in patients with hemorrhagic stroke. Surgical clipping and endovascular coiling are the mainstay of management for securing the aneurysm. After International Subarachnoid Aneurysm Trial (ISAT) and Barrow Ruptured Aneurysm Trial (BRAT) results, worldwide trend has shifted gradually in favor of endovascular management. Nonetheless, endovascular management was faced with some limitations, especially while treating giant, wide neck bifurcation, blister, and small uncoilable aneurysm. The recent introduction of new devices such as flow diverter stents, microstents, bifurcation devices, double-lumen balloon catheters, and microcoils have proved to be effective in overcoming the limitations of traditional aneurysm coiling. The authors present a review of recent advances in the endovascular management of cerebral aneurysm.
\end{abstract}

\section{Introduction}

The first catheterization of brain arteries was described by Luessenhop and Velasquez in $1964 .{ }^{1}$ Following that, another milestone in the form of detachable balloon was reported in cerebral aneurysm and carotid-cavernous fistulae. ${ }^{2}$ Further improvements were sought since detachable balloon had its inherent problems while treating aneurysms and carotid-cavernous fistulae. Guglielmi, an endovascular neurosurgeon, devised controllable, retrievable, detachable platinum coils for a safer and effective treatment of brain aneurysm in 1989. First human application of these coils was done in $1990{ }^{3}$ Later, Moret et al reported balloon remodeling techniques that achieved more complete aneurysm occlusion and were found to be more effective than conventional aneurysm coiling. ${ }^{4}$ Thereafter, the concept of the intracranial stent assisted aneurysm coiling with parent artery reconstruction was introduced by Henkes et al. ${ }^{5}$

International Subarachnoid Aneurysm Trial (ISAT) and Barrow Ruptured Aneurysm Trial (BRAT) showed significant lower morbidity and better safety of the endovascular treatment than surgical clipping. ${ }^{6}$ However, in the ISAT and BRAT trials approximately $50 \%$ and $32 \%$ of patients, respectively, were treated by endovascular approach. ${ }^{6,7}$ Longterm follow-up of ISAT trial showed decreased morbidity and dependency in the endovascular group compared with surgical group. ${ }^{8}$

Recent technical advances have enabled the possibility to treat majority of aneurysms, using endovascular means with significant reduction in recurrence rates. Management of the complex fusiform aneurysm, giant aneurysm, blister aneurysm, and small uncoilable aneurysm has been made possible by the recent introduction of flow diverter technology. Furthermore, endovascular treatment of the small distal branch wide neck aneurysms is now possible with introduction of intracranial microstents. Bifurcation devices have improved overall outcome of wide neck bifurcation aneurysm when treated using endovascular techniques. The authors present review of recent advances in endovascular treatment of cerebral aneurysm.

\section{Flow Diverter Stents (Endoluminal Flow Diversion)}

All flow diverters are braids with high pore density and low porosity (-Table 1). Flow diverter deployment modifies received

May 28, 2018

accepted

July 9, 2018

published online

August 31, 2018
DOI https://doi.org/

$10.1055 / \mathrm{s}-0038-1669478$.

ISSN 2277-954X.
C2018 Neurological Surgeons'

Society of India
License terms

(®) $\Theta \circledast$ 
Table 1 Product summary of flow diverter devices available in India

\begin{tabular}{|l|l|l|l|}
\hline Flow diverter & $\begin{array}{l}\text { Available } \\
\text { length }(\mathbf{m m})\end{array}$ & $\begin{array}{l}\text { Available } \\
\text { diameter }(\mathbf{m m})\end{array}$ & Design \\
\hline Pipeline (Medtronic) & $10-35$ & $2.5-5$ & 48 braided strands \\
\hline Surpass (Stryker) & $12-50$ & $2-5$ & 48,72 , and 96 braids-according to diameter of stent \\
\hline FRED (MicroVention) & $7-56$ & $3.5-5.5$ & Outer 16 braids and inner 48 braids \\
\hline SILK (Balt Extrusion) & $15-40$ & $2-5$ & 48 braided strands \\
\hline p64 (Phenox) & $12-36$ & $2.5-5$ & 64 braided strands \\
\hline
\end{tabular}

the intra-aneurysmal blood flow while maintaining the laminar flow inside the parent artery. The resultant intraaneurysmal stasis promotes progressive thrombosis within the aneurysm. Over a period of time, endothelium grows over the stent excluding the aneurysm completely with parent artery reconstruction and shrinking of aneurysm. Therefore, it leads to fewer recurrences when compared with traditional coiling. ${ }^{9}$ Flow diverter stents have transformed treatment of the giant aneurysm, which were managed with complex surgical techniques such as trapping and bypass (-Fig. 1 ).

\section{Flow Diverters in Anterior Circulation}

Pipeline embolization device was introduced in 2008 for treating intracranial aneurysm. Since then, to overcome the

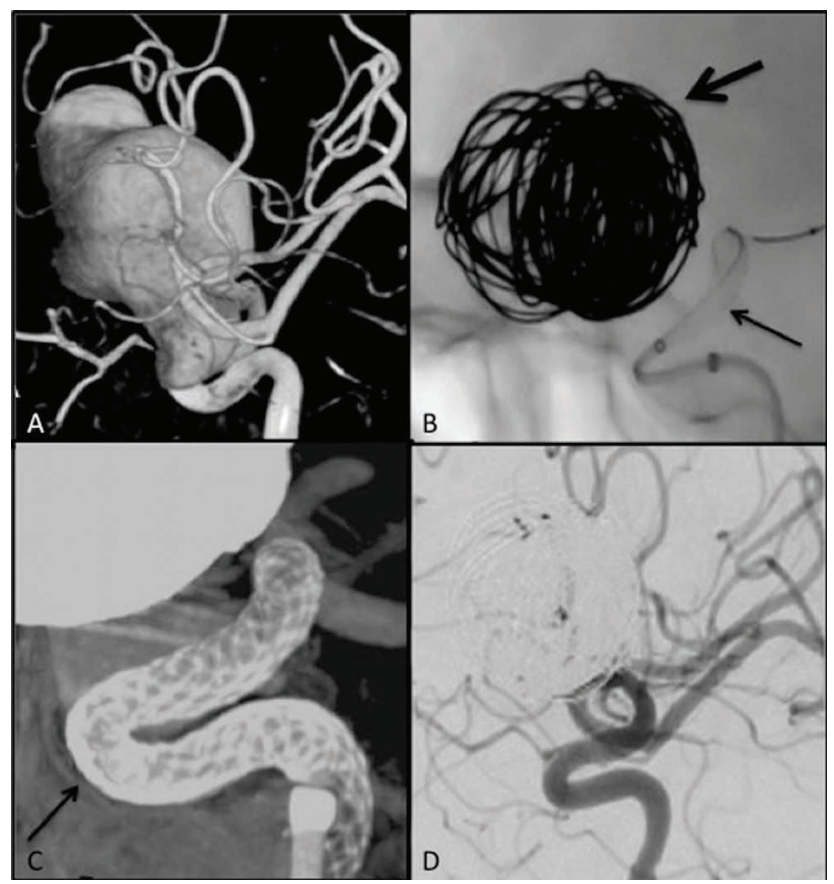

Fig. 1 A 35-year-old female patient presented with eye symptoms secondary to mass effect from the giant unruptured cavernous segment ICA aneurysm. 3D rotational angiogram surface shaded display image showing giant ICA aneurysm involving cavernous segment (A). Native image is showing flow diverter deployment (thin arrow in $\mathbf{B}$ ) across the aneurysm after partial coil embolization (thick arrow in $\mathbf{B}$ ) of the aneurysm sac. Vaso $\mathrm{CT}$ image post deployment showing well-apposed flow diverter even in curvature of cavernous segment ICA (arrow in C). Six-month follow-up angiogram showing complete occlusion of the aneurysm with parent artery reconstruction (D). shortcomings of the initial device, Pipeline Flex was introduced in 2014 with stiffer delivery wire and polytetrafluroethylene (PTFE) sleeves instead of capture coil. Favorable outcomes with the device were noted in multiple studies. PUFS (Pipeline for Uncoilable or Failed Aneurysms) study reported $93.4 \%$ and $95.2 \%$ complete aneurysm occlusion at the end of 3 and 5 years, respectively, with a good clinical outcome in $96.3 \%$ of patients. ${ }^{10}$

The PITA (The Pipeline Embolization Device for the Intracranial Treatment of Aneurysms) study again confirmed good occlusion rates (93\%) at 6 months. ${ }^{11}$ A meta-analysis revealed that flow diverters are particularly very effective in treating large and giant anterior circulation aneurysms with near-complete occlusion in $80 \%$ at 6 months. The early and delayed complication rates were $5.7 \%$ and $1.9 \%$, respectively, with low retreatment rates. ${ }^{12,13}$

\section{Flow Diverters in Blister Aneurysm}

Surgical and conventional endovascular treatment (coils and parent vessel occlusion) had high complication rate for the treatment of the blister aneurysm. Flow diversion is now being increasingly used to treat blister aneurysm. Conceptually, flow redirection is better with flow diverters as compared with the traditional overlapping stents. Recent meta-analysis showed significant better outcome of flow diversion in blister aneurysms compared with surgical arm as well as other endovascular techniques such as coiling, stent-assisted coiling, and parent artery occlusion. ${ }^{14,15}$ The author's experience of flow diverters in ruptured blister aneurysm showed complete occlusion in $89 \%$ with no repeat treatment or rebleed. ${ }^{16}$ Single flow diverter device with good wall apposition and stent compaction in the region of aneurysm neck leads to complete occlusion of blister aneurysm without significant complications ( - Fig. 2).

\section{Flow Diverters in Posterior Circulation Aneurysm}

Endovascular management of posterior circulation aneurysm using flow diverter stents is challenging because of the complex nature of disease and high risk of perforator ischemia. A meta-analysis of 225 posterior circulation aneurysm treated with flow diverter stents has showed procedure-related mortality rate of $15 \%$, with higher rate of complications, especially in patients with giant aneurysms and basilar artery aneurysms. The rate of complete aneurysm occlusion at 6-month digital subtraction angiography (DSA) was $84 \%$. Perforator occlusion accounted for $7 \%$ of all 
ischemic strokes (11\%). ${ }^{17}$ However, flow diverter is a viable option in the treatment of these aneurysms, allowing for vessel reconstruction and significantly better aneurysm occlusion (-Fig. 3 ).

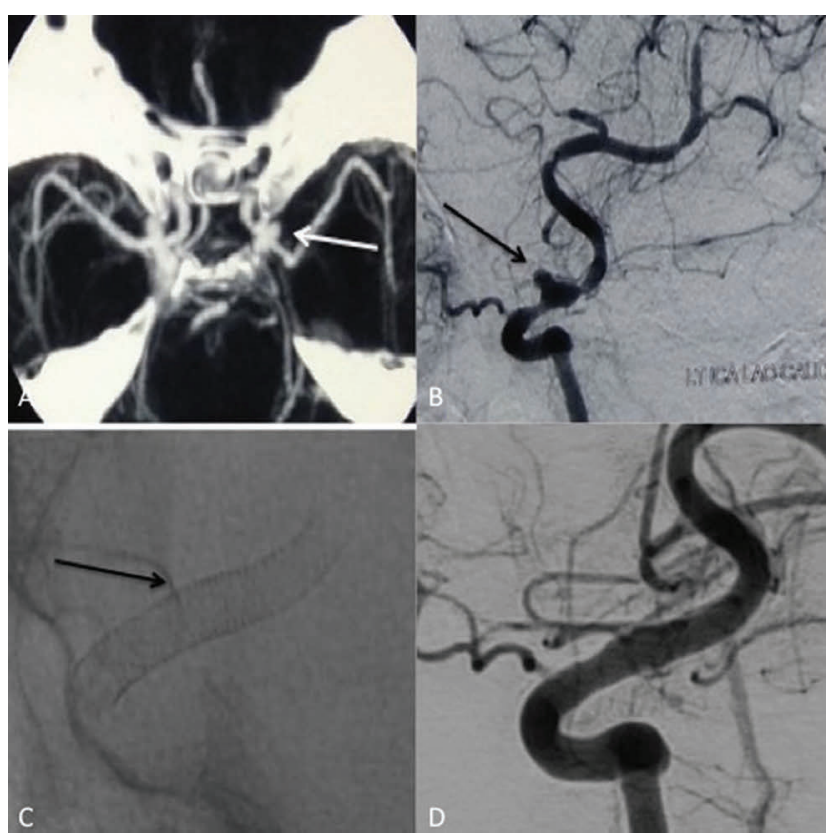

Fig. 2 A middle-aged woman presented with acute subarachnoid hemorrhage. CT angiography showing small aneurysm in left supraclinoid ICA (arrow in A). DSA confirmed the aneurysm in dorsal supraclinoid ICA (arrow in B)-typical location for blister aneurysms and interval size change compared with CT angiography. Distal intracranial arteries showed diffuse vasospasm. Flow diverter placement for the treatment of blister aneurysm with stent compaction near the aneurysmal segment of ICA (arrow in C). Six-month follow-up angiogram showing complete aneurysm occlusion with parent artery reconstruction (D).

\section{Complications of Flow Diverters}

The most common periprocedural complication in flow diverter treatment group is thromboembolic phenomenon. Using new antiplatelet agents such as Ticagrelor and Prasugrel has significantly reduced incidence of thromboembolic complications in our practice as these drugs have low probability of platelet resistance. Further, in a specific subset of patients in whom the aneurysm size is greater than $2.2 \mathrm{~cm}$, delayed clinical deterioration due to a transient increase in the perianeurysmal brain inflammation has been noted. ${ }^{12}$ Protective measures including prolonged steroid therapy and ventriculoperitoneal (VP) shunt insertion in certain groups of patients proved to be beneficial. Finally, delayed aneurysm rupture has been noted following flow diverter placement, especially for large and giant aneurysm. The potential mechanisms of delayed rupture include persistent inflow jet after treatment, thrombosis with expansion of the aneurysm due to stagnation of flow, and thrombus-induced inflammation of the aneurysm wall. ${ }^{12,13}$ The RADAR (Retrospective Analysis of Delayed Aneurysm Ruptures after Flow Diversions) study reported a 2.1\% risk of delayed ruptured for aneurysms larger than $10 \mathrm{~mm}$ in diameter, with a median time from treatment to rupture of 9 days. In the authors' experience, for large aneurysms of size greater than $10 \mathrm{~mm}$, partial coiling can be done followed by the flow diverter placement to prevent thrombus-induced inflammation as coil mass helps fragment the thrombus.

\section{New Advances in Flow Diverter Technology}

Technical advancements in flow diverter are focused on the following issues:

1. Low-profile delivery system (FRED Jr. MicroVention and p48-Phenox) are compatible with small-diameter

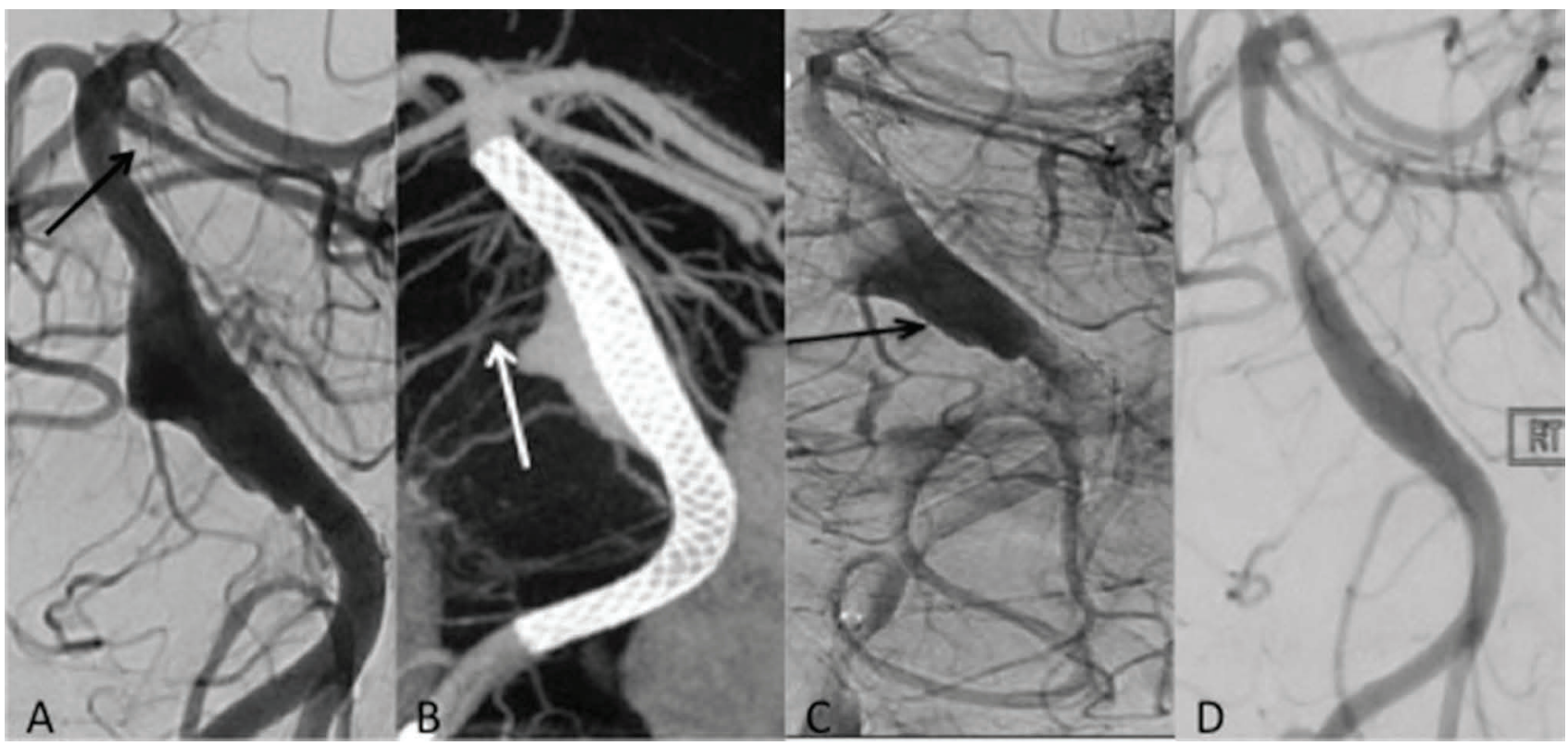

Fig. 3 A 45-year-old male patient presented with brainstem compression symptoms. DSA showed basilar artery fusiform aneurysm (arrow in A). Flow diverter was placed from right vertebral artery (V4 segment) to upper basilar artery across the fusiform aneurysm. Postprocedure Vaso CT showed good wall apposition of stent with maintained flow in the perforators from basilar artery even in aneurysmal segment (arrow in B). Postprocedure angiogram (late arterial phase) showed significant stasis inside the aneurysm sac (arrow in C). Follow-up angiogram after 6-month period showed complete aneurysm occlusion with parent artery reconstruction and maintained flow in branch arteries (D). 
microcatheter that allows for easy navigation to small distal arteries.

2. The Pipeline Shield Technology is a modification of device in which a synthetic phosphorylcholine polymer is bonded to the pipeline braid to reduce thrombogenecity. ${ }^{18}$ Still further studies are necessary to analyze its clinical utility.

\section{Intrasaccular Flow Diversion /Disruption}

Flow diversion for wide neck bifurcation aneurysm is limited by thromboembolic complication and side branch occlusion. Therefore, intrasaccular device that enables reconstruction of the anatomy at the neck while providing a robust scaffold to the coil mass appears to be a welcome tool to treat bifurcation aneurysms (-Table 2). These devices are placed within the aneurysm leading to aneurysm occlusion and progressive thrombosis.

\section{Woven EndoBridge}

This was introduced in 2011 as first intrasaccular device for the treatment of bifurcation aneurysm. It consists of braided nitinol wires, which help maintain the globular shape of the device (-Fig. 4A, B). Total metal coverage provided is between 35 and $45 \%$ and intended to maintain good wall apposition along the aneurysm sac including the neck leading to inflow disruption. The WEB device comes in two configurations: standard (SL [single layer] and DL [double layer]) and spherical SLS [single-layer sphere]). The WEB SL-EV (enhanced visualization) is the latest version of these devices and delivered through 0.017-in ID microcatheter. ${ }^{19}$

In 2016, the WEBCAST (WEB Clinical Assessment of Intrasaccular Aneurysm Therapy) study reported successful treatment outcomes in $85 \%$ of patients. The rate of thromboembolic events was $17.6 \%$, with a permanent deficit in one patient. ${ }^{20}$ Meta-analysis of all the available series showed complete or near-complete aneurysm occlusion that was observed in $80 \%$ aneurysms at the end of 1 year. ${ }^{19}$

\section{Luna Aneurysm Embolization System}

The Luna AES (aneurysm embolization system) is a selfexpanding double-layer nitinol mesh with platinum markers. It is delivered via a standard 0.027-in microcatheter and takes an ovoid shape within the aneurysm. Study conducted by Piotin et al showed $77 \%$ rate of complete or near-complete occlusion at the end of 1 year $(n=44)$. The authors concluded that the 12-month results demonstrated a good safety profile and good results on angiographic follow-up. ${ }^{21}$

Table 2 Overview of intrasaccular flow diversion/disruption devices

\begin{tabular}{|l|l|l|}
\hline Device & Retrievable & $\begin{array}{l}\text { Compatible } \\
\text { microcatheter }\end{array}$ \\
\hline WEB (Sequent Medical, Inc.) & Yes & 0.027 in ID \\
\hline $\begin{array}{l}\text { LUNA (Nfocus } \\
\text { Neuromedical) }\end{array}$ & Yes & 0.027 in ID \\
\hline Medina (Medtronic) & Yes & 0.021 in ID \\
\hline
\end{tabular}

\section{Medina}

The Medina embolic device (Medtronic) is a threedimensional (3D) coil made from shape-set core wire with outer filaments forming petals. The 3D petals constitute broader coil loops. This broader loop allows for stable anchoring of the coil mass within the aneurysm sac. ${ }^{22}$ Initial results in 11 unruptured aneurysms have showed complete or near-complete aneurysm occlusion in 10 patients and an enlarging neck remnant in 1 patient. ${ }^{23}$ Lobulated aneurysms can be treated effectively with Medina and coils combinations to avoid recurrences.

\section{Low-Profile Intracranial Stents}

\section{Braided Stent}

LVIS, LVIS Jr (MicroVention), Leo Plus, and Leo Plus Baby (Balt Extrusion) are the available braided stents in India for the treatment of the cerebral aneurysm. These are selfexpandable braided stents with closed cell construction and made of nitinol. The LVIS and Leo Plus stents are recommended for the larger vessels, whereas LVIS Jr and Leo

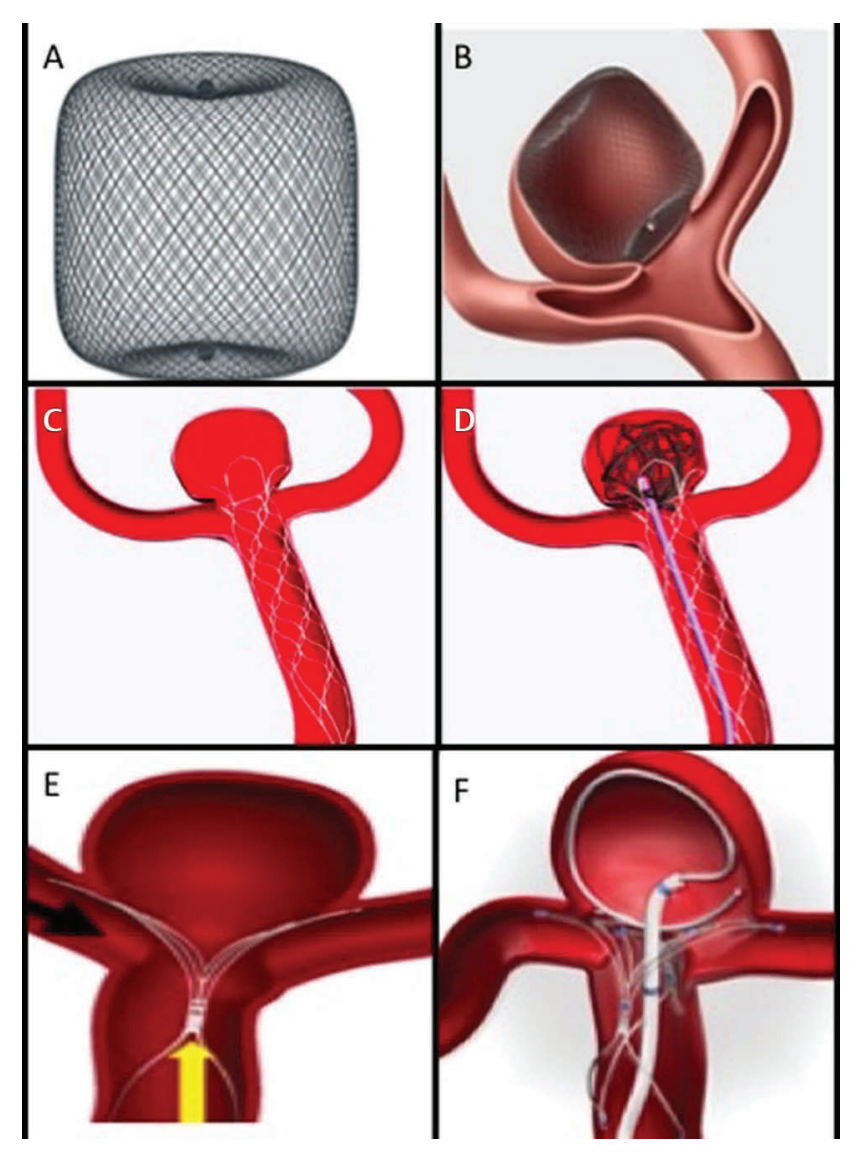

Fig. 4 Pictorial presentation of different bifurcation devices showing WEB intrasaccular (A), WEB deployed into the aneurysm sac (B, printed with permission from Sequent Medical), PCONUS with petals inside aneurysm sac (C), coiling microcatheter across the petals into aneurysm sac (D, printed with permission from Pulsar Vascular), PulseRider with both limbs in side branches (arrow in E), and coiling microcatheter inside the aneurysm sac through the device near neck ( $\mathbf{F}$, printed with permission from Phenox). 
Plus Baby are for smaller vessel up to $2 \mathrm{~mm}$ in diameter. The later stents can be used with ease beyond the circle of Willis as they are compatible with smaller and more flexible microcatheter systems. ${ }^{24}$ They have a relatively smaller cell size $(\sim 1.2 \mathrm{~mm}$ in Leo Plus, $0.9 \mathrm{~mm}$ in Leo Plus Baby, $1.0 \mathrm{~mm}$ in LVIS, and $1.5 \mathrm{~mm}$ in LVIS Jr), and therefore have high pore density and low porosity in comparison with conventional self-expandable intracranial stents. Furthermore, because the construct is a braid, it allows to create a shelf across the aneurysm sac and form an effective scaffold across the neck with a single device. The technique of "shelfing" reduces the need for additional devices and consequently the complication rates. One study of $78 \mathrm{pa}-$ tients demonstrated $82 \%$ aneurysm occlusion at 6-month follow-up with only $3 \%$ of cases with TIA, which is better than other intracranial stents. ${ }^{24}$ In authors' experience, using single microstents and shelfing technique coil embolization of wide neck bifurcation aneurysm has shown good long-term occlusion rates (-Fig. 5).

\section{Hybrid Stent}

Neuroform Atlas (Stryker) stent has been approved by the Food and Drug Administration (FDA) for the treatment of the wide neck intracranial saccular aneurysm. The stent has unique combination of closed cell design at the proximal end and with open cell design at the distal end, and therefore offers distinct advantages of both stent designs. Conformability (vessel wall apposition), easy delivery, precise placement of stent, and easy microcatheter access to the aneurysm sac are the important advantages of this stent.

\section{Double-Lumen Balloons Catheter}

Single-lumen balloon catheters had certain technical challenges such as less torquability with 0.010 -in microwire, poor stability, and difficult navigation, especially in tortuous anatomy. Further, development of double-lumen balloon catheters with 0.014 -in microwire compatibility provided better wire torquability, thereby helping the catheterization of appropriate branches near the aneurysm neck (- Table 3 ).
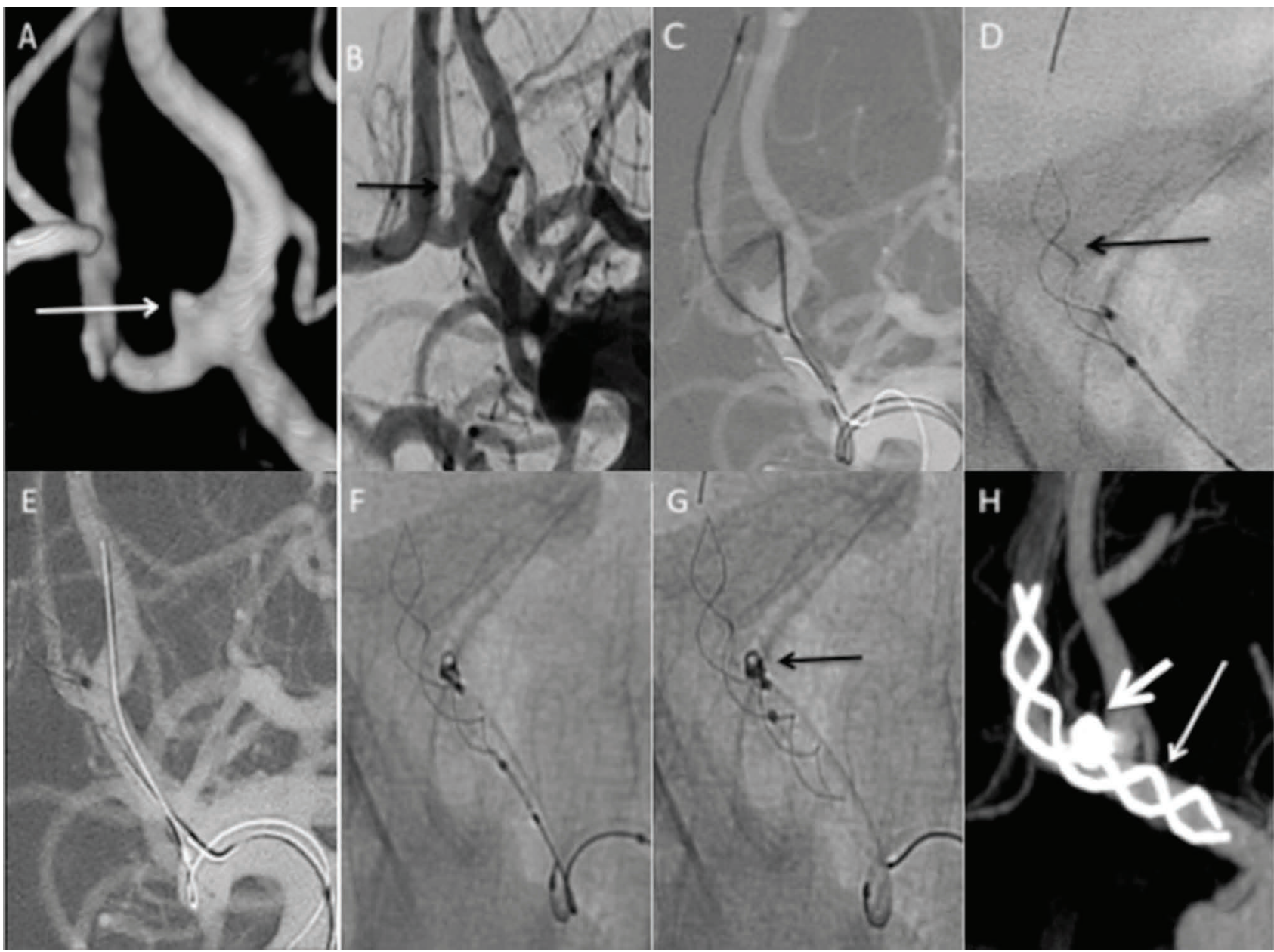

Fig. 5 A 48-year-old male patient presented with subarachnoid hemorrhage. Angiography showing small, sessile, broad-based anterior communicating artery (ACOM) aneurysm (perhaps a blister aneurysm) (arrows in A, B). Plan was to do stent-assisted coiling, with Leo Plus Baby stent. Stent microcatheter (Vasco 10) with microwire was placed in right A2 ACA from left A1 ACA. Due to small size of the aneurysm, it was difficult to have stable catheterization; hence, it was planned to partially deploy the stent with microcatheter in left A2 ACA (C). Aneurysm was later catheterized with the help of partially opened Leo stent $(2.5 \times 25)$, which acts as a scaffolding to support coiling microcatheter at the neck of the aneurysm (arrow in D). Aneurysm was then embolized using a 1.5- $\mathrm{mm} \times 4-\mathrm{cm}$ coil (E). Stent was then fully deployed, and coiling was completed (F, arrow in $\mathbf{G})$. Poststenting Vaso CT showing well-opposed stent (thin arrow) along right ACA with coil in the aneurysm (thick arrow) (H). 
Table 3 Technical details of available dual-lumen balloon catheters

\begin{tabular}{|l|l|l|l|l|}
\hline Balloon & Guidewire (in) & Length of balloon (mm) & Diameter of balloon (mm) & DMSO compactible \\
\hline Ascent (DePuy Synthes) & 0.014 & $7,9,10,15$ & 4,6 & Yes \\
\hline Scepter (MicroVention) & 0.014 & $10,15,20 / 11$ & 4 & Yes \\
\hline Eclipse 2L (Balt Extrusion) & 0.014 & $7 / 9,12,20$ & 6 & Yes \\
\hline
\end{tabular}

Compared with single-lumen balloon catheters, doublelumen balloon offers other distinct advantages:

1. Ability to deploy the low-profile stent in case of bailout options

2. Injection of liquid embolic agents, if required

3. Simultaneous mechanical and chemical angioplasty of severe vasospasm following acute subarachnoid hemorrhage (SAH) $)^{25}$

The Comaneci temporary bridging device (Rapid Medical) is a compliant radiopaque mesh, which temporarily bridges the neck of the aneurysm to support coil mass without compromising flow in the parent artery. One study reported on stable occlusion in 14 of 18 aneurysms treated using this device. Four patients required additional remodeling technique either stent or balloon. One patient had delayed parent artery occlusion probably owing to endothelial injury secondary to prolonged balloon inflation. ${ }^{26}$

\section{Smaller Coil}

Hypersoft helical and 3D coils (Target Nano, Stryker; Blockade, Balt Extrusion; Hydro Coils, MicroVention; and Axium Prime, eV3), in particular those with 1 to $1.5 \mathrm{~mm}$ in diameter, achieve higher packing density in small aneurysms. These very soft platinum coils may offer the neurointerventionist the possibility to fill smaller spaces and allow for the improved packing in small aneurysm. However, the longterm follow-up of a large series of patients is necessary for evaluation of the improvement of the recanalization rate. ${ }^{27}$

The authors' experience also showed improved packing density using these microcoils in small aneurysm as well as finishing coil in larger aneurysm.

\section{Bifurcation Support Devices}

Most of the bifurcation devices for wide neck aneurysm were only for the support of coil mass during the aneurysm treatment. Presently new devices offer the support as well as neck reconstruction in these aneurysm.

\section{pCONus}

The pCONus (Phenox GmbH) is a stent-like device with four petals at the distal end that rests on the inner wall of the sac. To create a scaffold that prevents coil prolapse, there is a meshwork at the base of the petals ( - Fig. 4C, D). The aneurysm sac can be catheterized through the mesh at the base of the petals. The device is compatible with standard microcatheter with an inner diameter of 0.021 in..$^{28,29}$ One retrospective study evaluated the safety and efficacy of pCONus with adjuvant coiling in unruptured wide neck bifurcation aneurysm. At 12 months complete occlusion was noted in $75 \%$ of patients $(n=12)$. Two cases had embolic complications and out of this one was directly related to the pCONus device. ${ }^{29}$ The latter generation pCONus 2 devices have six petals to provide a better scaffold at the level of the neck.

\section{Pulse Rider}

The Pulse Rider (Pulsar Vascular) is a bifurcation device-a self-expanding, nitinol implant that is available in both " $T$ " and "Y" configurations, intended to fit the geometry of the daughter vessels arising at the bifurcation. The device is available in different diameters and lengths with the key benefit being that the daughter branches do not need to be accessed to deploy the device ( - Fig. 4E, F). These petals offer neck protection regardless of whether they are positioned within the sac or daughter branches. ${ }^{30}$

A prospective, nonrandomized, single-arm clinical trial showed near-complete occlusion in $87.9 \%$ and good outcomes in $94 \%$ of patients at 6 months. ${ }^{31}$ This device is not yet available in India.

\section{Conclusion}

Technological advancements in endovascular treatment methods have resulted in a sea change in the approach and treatment to cerebral aneurysms. Many of these novel devices represent new solutions to commonly encountered challenges in treatment of complex aneurysms, including giant aneurysm, blister aneurysm, nonsaccular posterior circulation aneurysm, and wide neck bifurcation aneurysm. Better safety profile and good long-term occlusion rates in multiple clinical trials have proved to be pivotal in the approval of new devices in the management of cerebral aneurysm.

\section{References}

1 Guglielmi G. History of endovascular endosaccular occlusion of brain aneurysms: 1965-1990. Interv Neuroradiol 2007;13(3):217-224

2 Serbinenko FA. Balloon catheterization and occlusion of major cerebral vessels. J Neurosurg 1974;41(2):125-145

3 Guglielmi G, Viñuela F, Dion J, Duckwiler G. Electrothrombosis of saccular aneurysms via endovascular approach. Part 2: preliminary clinical experience. J Neurosurg 1991;75(1):8-14

4 Moret J, Cognard C, Weill A, Castaings L, Rey A. The "remodelling technique" in the treatment of wide neck intracranial aneurysms. angiographic results and clinical follow-up in 56 cases. Interv Neuroradiol 1997;3(1):21-35

5 Henkes H, Bose A, Felber S, Miloslavski E, Berg-Dammer E, Kühne D. Endovascular coil occlusion of intracranial aneurysms assisted by a novel self-expandable nitinol microstent (neuroform) Interv Neuroradiol 2002;8(2):107-119 
6 Molyneux AJ, Kerr RSC, Yu L-M, et al; International Subarachnoid Aneurysm Trial (ISAT) Collaborative Group. International subarachnoid aneurysm trial (ISAT) of neurosurgical clipping versus endovascular coiling in 2143 patients with ruptured intracranial aneurysms: a randomised comparison of effects on survival, dependency, seizures, rebleeding, subgroups, and aneurysm occlusion. Lancet 2005;366(9488):809-817

7 Goel G, Gupta V, Chinchure S, Gupta A, Kaur G, Jha AN. A decade after International Subarachnoid Aneurysm Trial: coiling as a first choice treatment in the management of intracranial aneurysms-technical feasibility and early management outcomes. Asian J Neurosurg 2014;9(3):137-143

8 Molyneux AJ, Birks J, Clarke A, Sneade M, Kerr RSC. The durability of endovascular coiling versus neurosurgical clipping of ruptured cerebral aneurysms: 18 year follow-up of the UK cohort of the International Subarachnoid Aneurysm Trial (ISAT). Lancet 2015;385(9969):691-697

9 Fiorella D, Lylyk P, Szikora I, et al. Curative cerebrovascular reconstruction with the pipeline embolization device: the emergence of definitive endovascular therapy for intracranial aneurysms. J Neurointerv Surg 2009;1(1):56-65

10 Becske T, Brinjikji W, Potts MB, et al. Long-term clinical and angiographic outcomes following pipeline embolization device treatment of complex internal carotid artery aneurysms: five-year results of the Pipeline for Uncoilable or Failed Aneurysms Trial. Neurosurgery 2017;80(1):40-48

11 Nelson PK, Lylyk P, Szikora I, Wetzel SG, Wanke I, Fiorella D. The pipeline embolization device for the intracranial treatment of aneurysms trial. AJNR Am J Neuroradiol 2011;32(1):34-40

12 Rajah G, Narayanan S, Rangel-Castilla L. Update on flow diverters for the endovascular management of cerebral aneurysms. Neurosurg Focus 2017;42(6):E2

13 Gupta V, Parthasarathy R, Jha AN. Endovascular reconstruction of aneurysms with a complex geometry. Neurol India 2016;64(7, Suppl):S24-S31

14 Rouchaud A, Brinjikji W, Cloft HJ, Kallmes DF. Endovascular treatment of ruptured blister-like aneurysms: a systematic review and meta-analysis with focus on deconstructive versus reconstructive and flow-diverter treatments. AJNR Am J Neuroradiol 2015;36(12):2331-2339

15 Mokin M, Chinea A, Primiani CT, et al. Treatment of blood blister aneurysms of the internal carotid artery with flow diversion. J Neurointerventional Surg 2018. doi: 10.1136/ neurintsurg-2017-013701 [Epub ahead of print]

16 Chinchure SD, Gupta V, Goel G, Gupta A, Jha A. Subarachnoid hemorrhage with blister aneurysms: endovascular management. Neurol India 2014;62(4):393-399
17 Wang C-B, Shi W-W, Zhang G-X, Lu H-C, Ma J. Flow diverter treatment of posterior circulation aneurysms. A meta-analysis. Neuroradiology 2016;58(4):391-400

18 Martínez-Galdámez M, Lamin SM, Lagios KG, et al. Periprocedural outcomes and early safety with the use of the Pipeline Flex embolization device with Shield Technology for unruptured intracranial aneurysms: preliminary results from a prospective clinical study. J NeuroInterventional Surg 2017; 9(8):772-776

19 Pierot L, Gubucz I, Buhk JH, et al. Safety and efficacy of aneurysm treatment with the WEB: results of the WEBCAST 2 Study. AJNR Am J Neuroradiol 2017;38(6):1151-1155

20 Clajus C, Strasilla C, Fiebig T, Sychra V, Fiorella D, Klisch J. Initial and mid-term results from 108 consecutive patients with cerebral aneurysms treated with the WEB device. J Neurointerv Surg 2017:411-417

21 Piotin M, Biondi A, Sourour N, Blanc R. O-036 treatment of intracranial aneurysms with the LUNA AES: midterm clinical and angiographic follow-up. J NeuroInterventional Surg 2014;6 (Suppl 1):A19-A20

22 Aguilar Perez M, Bhogal P, Martinez, Moreno R, Bäzner H, Ganslandt O, Henkes H. The Medina Embolic Device: early clinical experience from a single center. J Neurointerv Surg 2017;9(1):77-87

23 Turk AS, Maia O, Ferreira CC, Freitas D, Mocco J, Hanel R. Periprocedural safety of aneurysm embolization with the Medina Coil System: the early human experience. J Neurointerv Surg 2016;8(2):168-172

24 Poncyljusz W, Biliński P, Safranow K, et al. The LVIS/LVIS Jr. stents in the treatment of wide-neck intracranial aneurysms: multicentre registry. J Neurointerv Surg 2015;7(7):524-529

25 Pukenas B, Albuquerque FC, Weigele JB, Hurst RW, Stiefel MF. Use of a new double-lumen balloon catheter for single-catheter balloon-assisted coil embolization of intracranial aneurysms: technical note. Neurosurgery 2011;69(1, Suppl Operative):ons8-ons12, discussion ons12-ons13

26 Fischer S, Weber A, Carolus A, Drescher F, Götz F, Weber W. Coiling of wide-necked carotid artery aneurysms assisted by a temporary bridging device (Comaneci): preliminary experience. J Neurointerv Surg 2017;9(11):1039-1097

27 Jindal G, Miller T, Beaty N, Puri A, Gandhi D. Ultra-small diameter coils for treatment of intracranial aneurysms. Interv Neuroradiol 2015;21(1):50-54

28 Pérez MA, Bhogal P, Moreno RM, et al. Use of the pCONus as an adjunct to coil embolization of acutely ruptured aneurysms. J Neurointerv Surg 2017;9(1):39-44

29 Lubicz B, Morais R, Alghamdi F, Mine B, Collignon L, Eker OF. The pCONus device for the endovascular treatment of wide neck bifurcation aneurysms. J Neurointerv Surg 2016;8(9):940-944

30 Mukherjee S, Chandran A, Gopinathan A, et al. PulseRider-assisted treatment of wide-necked intracranial bifurcation aneurysms: safety and feasibility study. J Neurosurg 2017;127(1):61-68

31 Gory B, Spiotta AM, Di Paola F, et al. PulseRider for treatment of wide-neck bifurcation intracranial aneurysms: 6-month results. World Neurosurg 2017;99:605-609 